JURNAL RISET REKAYASA ELEKTRO

Vol.3, No.2, Desember 2021, Hal. 111 118

P-ISSN: 2685 - 4341

E-ISSN: 2685 - 5313

\title{
Rancang Bangun Alat Bantu Mobilitas Tunanetra Dan Penentu Lokasi Menggunakan Global Positioning System Tracking Berbasis Internet Of Things
}

\author{
Rifqi Prima Anggara ${ }^{1}$, Arif Johar Taufiq ${ }^{2}$ \\ Program Studi S1 Teknik Elektro, Universitas Muhammadiyah Purwokerto \\ Fakultas Teknik dan Sains, Universitas Muhammadiyah Purwokerto
}

\section{Informasi Makalah}

Dikirim, 1 September 2021

Direvisi, 25 November 2021

Diterima, 7 Desember 2021

\section{Kata Kunci:}

GPS

Internet Of Things

Alat Bantu Tunanetra

Kodular

\begin{abstract}
INTISARI
Hambatan yang sering dialami penyandang tunanetra adalah mengetahui adanya penghalang, genangan air, dan lokasi tujuan. Keadaan ini menimbulkan kekhawatiran bagi keluarga tunanetra dalam mengetahui keberadaannya. Untuk itu, diperlukan alat yang dapat membantu penyandang tunanetra agar dapat mengetahui adanya penghalang, air dan lokasi tunanetra. Metode yang digunakan untuk membuat alat banti ini dengan menelaah referensi dan penelitian sebelumnya, kemudian mengembangkan dengan tambahan fitur baru: berupa tambahan indikator suara dan alat terhubung dengan jaringan internet melalui IOT. Alat bantu dilengkapi dengan tombol emergency saat terjadi keadaan darurat. Alat bantu juga dipasang tiga sensor ultrasonik HC-SR04 depan, kanan, dan kiri sebagai pendeteksi halangan, sensor soil moisture sebagai pendeteksi air, DF player mini yang terhubung ke speaker sebagai indikator suara dan modul GPS sebagai pendeteksi lokasi. Hasil pengujian alat bantu tongkat ini dapat mendeteksi halangan yang ada di depan sensor ultrasonik sesui yang diinginkan yaitu jarak $<70 \mathrm{~cm}$ dan dapat mendeteksi air dengan kedalaman genangan $>2 \mathrm{~cm}$ melalui sensor soil moisture. Informasi adanya halangan dan petunjuk arah telah dapat diucapkan oleh DF Player Mini yang terhubung ke speaker. Alat bantu ini mampu memberikan informasi keberadaan pengguna melalui Smartphone pada aplikasi Kodular berupa tampilan lokasi Google Maps di hanphone orang tua atau saudaranya. Tongkat ini juga dilengkapi dengan tombol emergency untuk mengirimkan pesan ke email yang telah didaftarkan saat dalam keadaan darurat.
\end{abstract}

\section{ABSTRACT}

Obstacles that blind people often experience know the existence of obstacles, water puddles, and the destination's location. This situation raises concern for blind families in knowing their whereabouts. For that, we need a tool that can help blind people to be able to find out the presence of obstacles, water and the location of the blind. The method used to make this tool is by reviewing references and previous research, then developing it with additional new features: other voice indicators and devices connected to the internet network via IoT. The tool is equipped with an emergency button in case of an emergency. There are also three ultrasonic sensors (HC-SR04) in front, right, and left to detect obstacles, a soil moisture sensor to detect water, a mini DF player connected to the speaker as a sound indicator and a GPS module to see a location. The test results of this stick tool can detect obstacles in front of the ultrasonic sensor as desired. Namely, a distance of $<70 \mathrm{~cm}$ can detect water with a puddle depth of $>2 \mathrm{~cm}$ through a soil moisture sensor. Obstacle indicators and directions can be spoken by the DF Player Mini connected to the speaker. This tool can provide information on the user's presence through a smartphone on a coded application to display Google Maps location on the cellphone of a parent or sibling. This stick is also equipped with an emergency button to send a message to the registered email when in an emergency..

\footnotetext{
Korespondensi Penulis:

Rifgi Prima Anggara

Program Studi Teknik Elektro

Universitas Muhammadiyah Purwokerto

JL. Raya Dukuhwaluh Purwokerto, 53182

Email: rifqianggara5@gmail.com
} 


\section{PENDAHULUAN}

Menurut Bapan Pusat Statistik data jumlah tunanetra di Indonesia sekitar 3,75 juta, sedangkan penyandang tunanetra anak-anak sekitar $40 \%$ dari 3,75 juta tersebut [1].Salah satu alat untuk membantu penyandang tunanetra ketika berjalan adalah dengan menggunakan tongkat yang berfungsi sebagai navigasi ketika penyandang tunanetra berjalan. Penyandang tunanetra terkadang kesulitan untuk menghindari rintangan yang ada disekitarnya, seperti menghindari benda padat, menaiki tangga, melalui jalan menanjak dan lain sebagainya. Penyandang tunanetra pun terkadang tersesat atau terjadi sesuatu dengan dirinya dijalan terkadang susah untuk menghubungi keluarganya. Untuk mengatasi persoalan tersebut, dengan teknologi yang berkembang saat ini dapat diterapkan pada tongkat penyandang tunanetra.

Andreas dkk [2] telah membuat tongkat bantu tunanetra berbasis arduino uno dengan fitur: peringatan bunyi buzzer, getaran dan kedip LED, jarak deteksi antara $50 \mathrm{~cm}$ sampai $150 \mathrm{~cm}$ [2], sedangkan Kamila [3] meneliti hal yang sama dengan tambahan fitur jika ada genangan air akan membunyikan buzzer. Supriyadi berhasil merealisasikan alat bantu jalan penyandang tunanetra yang dilengkapi dengan sebuah GPS yang terhubung dengan sebuah mikrokontroler ESP32 untuk mengolah data lokasi yang berupa longitude dan latitude. Data lokasi tersebut kemudian dikirim ke sebuah webserver dengan bantuan sebuah modem GSM, mampu memberikan informasi lokasi keberadaan penyandang tunanetra melalui sebuah Smartphone berupa tampilan lokasi pada Google Maps, tongkat dilengkapi juga dengan sebuah Panic Button yang bisa memberikan alarm ke layar smarphone setelah diaktifkan, ketika penyandang tunanetra sedang dalam keadaan darurat [4]. Nasution telah mengembangkan alat bantu tongkat tunanetra dengan fitur suara, koordinat GPS dan emergency call [5]. Berdasarkan penelitian sebelumnya maka akan dirancang alat berupa tongkat pemandu tunanetra berbasis Internet of Things (IOT) untuk membantu tunanetra dengan fitur: informasi suara halangan, tombol darurat serta tambahan jika ada genangan air. Selain itu alat ini juga dilengkapi dengan GPS yang tekoneksi ke Smartphone keluarga tunanetra untuk memonitoring penyandang tunanetra ketika sedang diluar rumah dan bisa berkomunikasi antara keluarga dan penyandang tunanetra serta terdapat tombol emergency atau call notification yang dapat mengirimkan lokasi penyandang tunanetra kepada keluarga ketika dalam bahaya dimana semua sistem itu telah terkoneksi ke IOT pada android menggunakan aplikasi Kodular [6], [7], [8], [9], [10]. Alat dirancanng berupa tongkat yang ditambahkan dengan roda yang bertujuan untuk mendeteksi adanya lubang, batu dan gundukan ketika sedang berjalan. Pada makalah ini akan dibahas mulai dari pendahuluan, metode, hasil kesimpulan.

\section{METODE PENELITIAN}

\subsection{Alur Penelitian}

Pelaksanaan penelitian ini dilakukan dalam beberapa tahapan yang akan dijelaskan pada Gambar 1 .

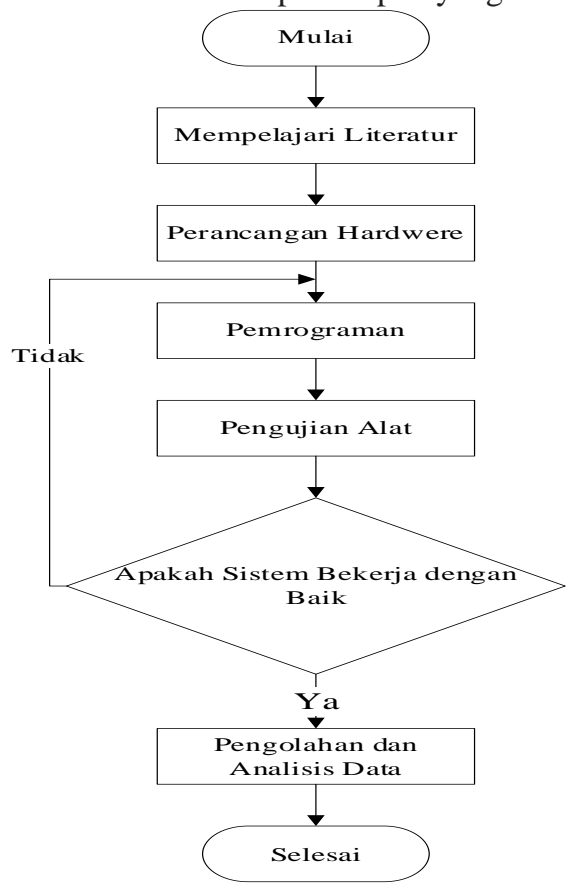

Gambar 1. Alur penelitian

Langkah penelitian yaitu: Mempelajari literatur: tahapan ini merupakan langkah pertama yang wajib dilakukan didalam sebuah penelitian karena mempelajari literatur yang berkaitan dengan perancangan sistem 
yang dibuat merupakan sebuah pondasi dalam sistem agar dapat menentukan langkah selanjutnya. Mempelajari literatur dengan baik yaitu bersumber dari buku, jurnal, penelitian terdahulu. Perancangan sistem: tahap kedua yaitu merancang sebuah sistem. Perancangan sistem ini dibagi menjadi dua bagian yaitu perancangan hardware dan perancangan software. Perancangan hardware ini dirancang dengan menggunakan sensor ultrasonik HC SR 04 sebagai pendeteksi objek atau halangan yang ada dihadapan pengguna, yang bertujuan agar pengguna alat dapat mengetahui atau mendapatkan peringatan dini bahwa disekitar terdapat objek atau halangan melalui speaker untuk memberikan keluaran berupa suara. Sistem ini dilengkapi pula dengan GPS dan sebuah sistem tombol emergency yang yang jika ditekan maka akan mengirimkan sinyal yang memberikan informasi lokasi dari pengguna alat yang dikirimkan melalui email ke penerima yang telah didaftarkan.Perancangan software dilakukan dengan membuat sebuah database yang dapat menerima data dari sistem hardware secara real time serta dapat terkoneksi dengan jaringan internet. Database real time dibuat dengan salah satu platform database bernama Firebase yang dikembangkan oleh Google. Kemudian pembuatan sebuah aplikasi Android melalui sebuah web app yaitu Kodular.io. Aplikasi ini difungsikan sebagai penampil data yang dikirimkan oleh sistem hardware dan juga dalam aplikasi android ini digunakan sebagai media penyimpanan data.

Pemrograman: dalam menerjemahkan diagram alir pada suatu sistem, dibutuhkan bahasa pemrograman, salah satunya bahasa C. Pemilihan bahasa pemrograman ini didasarkan pada kemudahan dalam memahami dan membuat suau program, serta banyaknya literatur yang bisa digunakan. Pembuatan program pada penelitian ini menggunakan IDE (Integrated Development Environment) Arduino sebagai software compiler dan downloader. Pengujian alat: setelah sistem telah selesai dirancang dan di program, maka langkah selanjutnya adalah menguji alat. Pengujian alat dilakukan guna mengetahui apabila terjadi kesalahan maupun kinerja alat yang tidak sesuai harapan agar dapat diperbaiki menjadi sebuah sistem yang ideal. Pengolahan Data dan Analisis: tahapan ini merupakan tahapan terakhir yaitu mengolah data yang telah didapat dari hasil pengujian.

\subsection{Alat dan Bahan}

Alat dan bahan yang digunakan dalam penelitian ini yaitu: Baterai Li-po, Arduino Nano, ESP 32, Modul GPS Neo Ublox M6, Sensor Ultrasonik HC-SR04, Sensor Soil Moisture, MiFi, Android, DF Player Mini, Speaker, Modul Stepdown LM2596, SD Card, Tongkat, serta perangkat lunak: Arduino IDE, Fritzing, Kodular App Creator, Google Firebase Console

\subsection{Blok Diagram Sistem}

Proses kerja alat bantu mobilitas tunanetra ini terdiri dari beberapa bagian utama antara lain: perangkat proses berupa arduino nano, ESP32 sebagai proses membaca GPS secara real time. Perangkat masukan meliputi: sensor ultrasonik, sensor soil moisture, push button, GPS Ublox Neo M6. Perangkat komunikasi meliputi: MiFi, google firebase dan android, sedangkan perangkat luaran meliputi speaker dan LED.

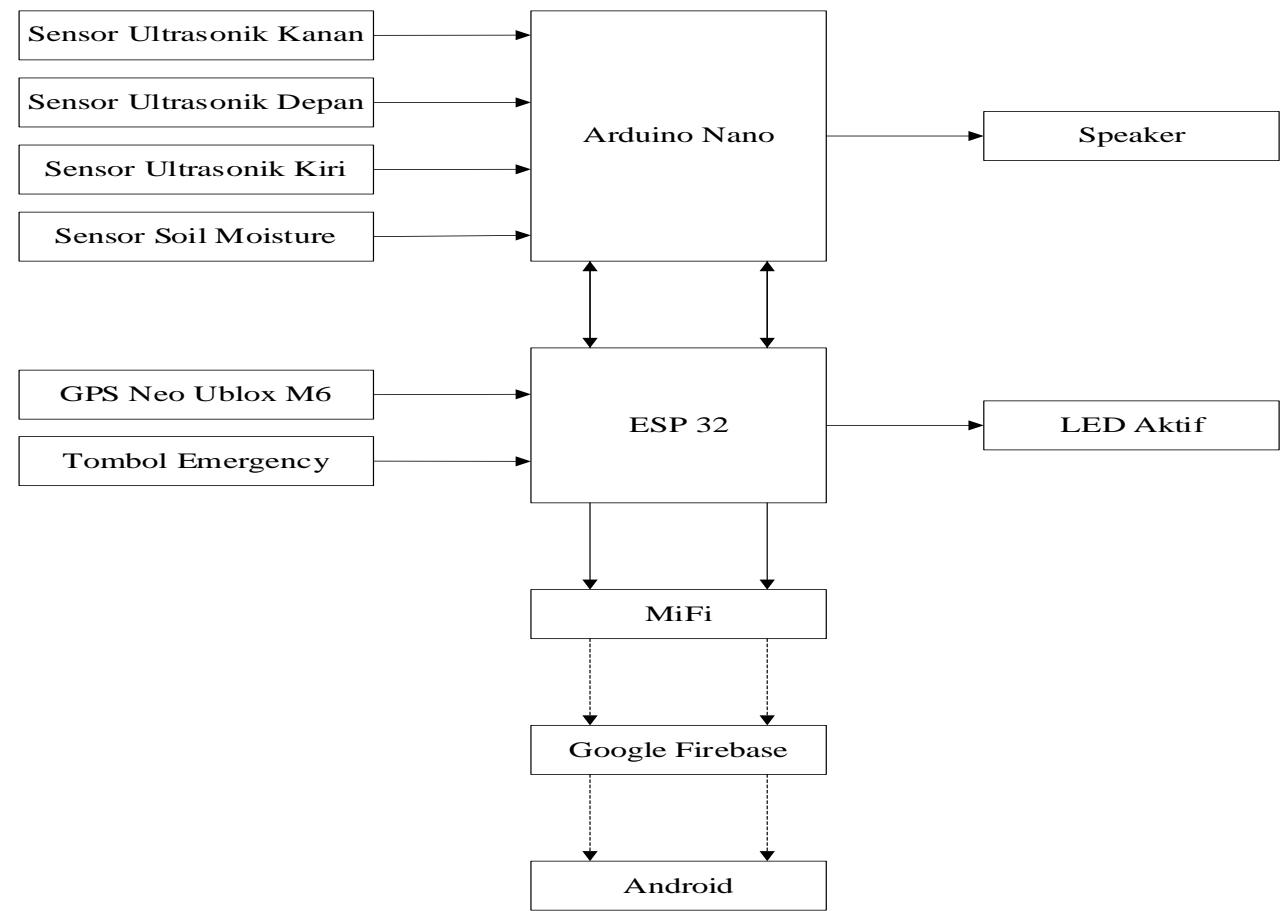

Gambar 2. Diagram Blok Sistem 
Pada Gambar 2 terdapat perangkat masukan ke arduino nano berupa sensor ultrasonik dan sensor soil moisture apabila sensor tersebut aktif maka akan diproses atau dikontrol oleh arduino nano, kemudian akan mengirimkan data ke DF Player Mini untuk menghasilkan luaran suara dari speaker. Modul ESP32 terdapat perangkat masukant berupa sinyal GPS dan tombol emergency. Data sinyal GPS tersebut dikirimkan ke ESP32 kemudian ke firebase menuju ke android. Diagram alir sistem kerja alat seperti pada Gambar 3.

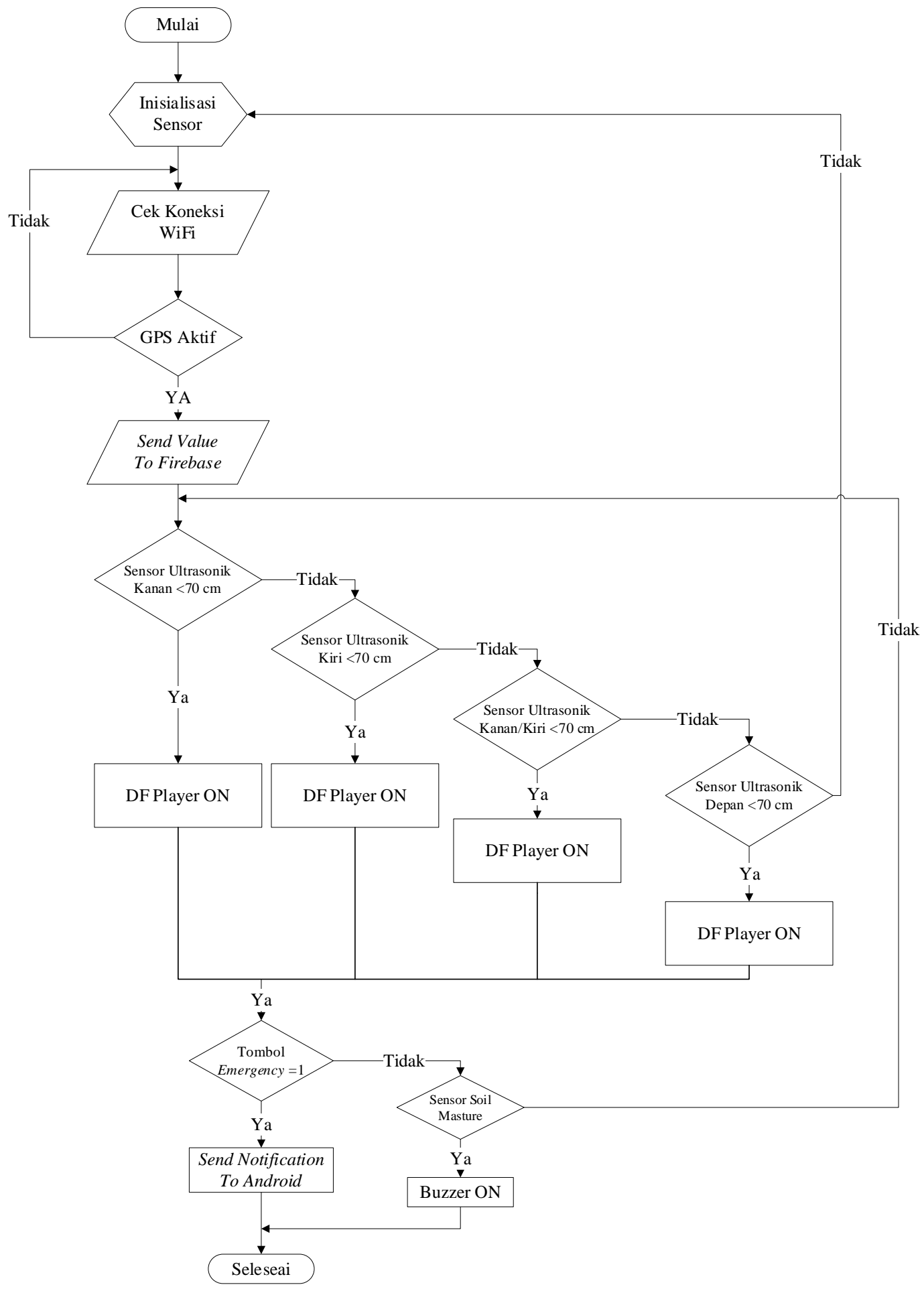

Gambar 3. Diagram alir sistem kerja alat 
Pada Gambar 3 menjelaskan cara kerja sistem alat bantu mobilitas tunanetra dan penentu lokasi menggunakan Global Positioning System Tracking berbasis Internet of Things sebagai berikut: Diawali dengan inisialisasi sensor selanjutnya sistem akan cek koneksi wifi untuk memastikan ESP32 sudah terkoneksi ke wifi. Cek GPS aktif untuk mengetahui lokasi alat bantu mobilitas tunanetra secara real time, kirim data to Firebase untuk mengirimkan data koordinat dari GPS menuju firebase. Sensor Ultrasonik berfungsi sebagai pendeteksi halangan diatur pada jarak aman $<70 \mathrm{~cm}$ dan sensor soil moisture sebagai pendeteksi air. Luaran dari sensor ultrasonik dan sensor soil moisture diproses dan dikonversi oleh mikrokontroler menjadi suara, selanjutnya pengguna alat dapat mendengar suara hasil suara konversi dari mikrokontroler ke speaker atau earphone. Ketika tombol emergency ditekan atau bernilai 1 maka sistem akan mengirimkan notification titik koordinat lokasi alat ini ke android melalui G-Mail.

\section{HASIL DAN PEMBAHASAN}

Hasil dari penelitian yang telah dilakukan menunjukan bahwa alat bantu mobilitas tunanetra, Gambar 4 (a) dan penentu lokasi menggunakan global positioning system tracking berbasis internet of things menggunakan 3 buah sensor ultrasonik HC-SR04 dengan masing-masing sensor ultrasonik mendeteksi objek dari jarak $0-70 \mathrm{~cm}$, dari hasil pengukuran, sensor ultrasonik bekerja dengan baik dapat mendeteksi halangan sesuai dengan jarak yang telah ditentukan

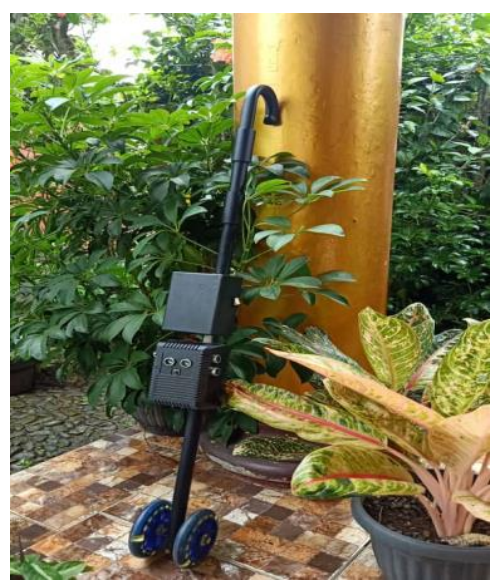

(a)

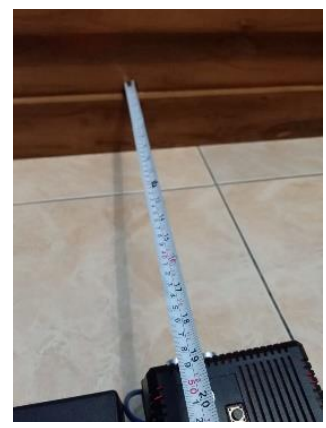

(b)

Gambar 4. (a) Alat bantu bentuk jadi dan (b) pengukuran pengujian jarak

Selain sensor ultrasonik pada alat mobilitas tunanetra ini juga terdapat sensor soil moisture yang digunakan untuk mendeteksi adanya genangan air dengan kedalaman air lebih dari $2 \mathrm{~cm}$, data pengamatan pad tabel 1 .

Tabel 1. Hasil Pengujian Sensor Air

\begin{tabular}{ccc}
\hline No & Kondisi Sekitar & Suara Speaker \\
\hline 1 & Genangan air dengan kedalaman $>2 \mathrm{~cm}$ & Bunyi (“Awas ada air”) \\
2 & Kering & Tidak Bersuara \\
\hline
\end{tabular}

Pengujian ini dilakukan dengan berjalan menggunakan alat bantu mobilitas tunanetra dengan dua kondisi yang berbeda, kondisi pertama berjalan dengan melewati genangan air dan kondisi kedua berjalan tanpa ada genangan air.Adapun indikator berupa suara dapat diaktifkan melalui DF player mini dengan bantuan speaker sesuai dengan perintah program. Pada DF player mini terdapat 10 suara dengan masing-masing kondisi yang berbeda sebagai berikut: Apabila alat ini ON maka suara 9 akan berbunyi dengan kalimat "Alat mobilitas tunanetra telah aktif" menandakan alat bantu mobilitas tunanetra siap digunakan. Apabila sensor ultrasonik kanan mendeteksi halangan < 70cm, suara 1 akan berbunyi dengan kalimat "di kanan ada halangan" menandakan ada halangan di depan. Apabila sensor ultrasonik depan mendeteksi halangan $<70 \mathrm{~cm}$, suara 2 akan berbunyi dengan kalimat "di depan ada halangan" menandakan ada halangan di sebelah kanan. Apabila sensor ultrasonik kiri mendeteksi halangan $<70 \mathrm{~cm}$, suara 3 akan berbunyi dengan kalimat "di kiri ada halangan" menandakan ada halangan di sebelah kiri. Apabila sensor ultrasonik depan dan sensor ultrasonik kiri mendeteksi halangan $<70 \mathrm{~cm}$ secara bersamaan, suara 4 akan berbunyi dengan kalimat "Silahkan belok kanan" menandakan ada halangan di depan dan di sebelah kiri. Apabila sensor ultrasonik kanan dan sensor ultrasonik 
kiri mendeteksi halangan $<70 \mathrm{Cm}$ secara bersamaan, suara 5 akan berbunyi dengan kalimat "Silahkan maju" menandakan ada halangan di sebelah kanan dan di sebelah kiri. Apabila sensor ultrasonik depan dan sensor ultrasonik kanan mendeteksi halangan $<70 \mathrm{~cm}$ secara bersamaan, suara 6 akan berbunyi dengan kalimat "Silahkan belok kiri" menandakan ada halangan di depan dan di sebelah kanan. Apabila sensor ultrasonik depan, sensor ultrasonik kanan, dan sensor ultrasonik kiri mendeteksi halangan $<70 \mathrm{~cm}$ secara bersamaan, suara 7 akan berbunyi dengan kalimat "Silahkan putar balik" menandakan ada halangan di depan, di sebelah kanan dan di sebelah kiri. Apabila sensor soil moisture mendeteksi air dengan kedalaman air $>2 \mathrm{~cm}$, maka suara 10 akan berbunyi dengan kalimat "awas ada air". Apabila menu panggil pada aplikasi kodular ditekan maka suara 9 pada speaker berbunyi dengan kalimat "ada panggilan silahkan pulang sekarang". Adapun pengujian yang telah dilakukan Df player mini bekerja dengan baik dan sesuai dengan suara yang telah diprogram. Pengujian modul GPS dijelaskan pada Tabel 2 dan tampilan lokasi tongkat ada dipihak keluarga terlihat pada Gambar 5 dan Gambar 6. Pengujian modul GPS bertujuan untuk mengukur keakuratan deteksi lokasi oleh modul GPS dibandingkan dengan deteksi lokasi oleh Google Maps.

Tabel 2. Pengujian Modul GPS

\begin{tabular}{|c|c|c|c|c|c|c|}
\hline Tempat & Datetime & $\begin{array}{c}\text { Latitude } \\
\text { (Modul } \\
\text { GPS) }\end{array}$ & $\begin{array}{c}\text { Longitude } \\
\text { (Modul } \\
\text { GPS) }\end{array}$ & $\begin{array}{c}\text { Latitude } \\
\text { (Google } \\
\text { Maps) }\end{array}$ & $\begin{array}{c}\text { Longitude } \\
\text { (Google } \\
\text { Maps) }\end{array}$ & Akurasi \\
\hline Di Luar & 28-06- & -7.56919 & 109.02681 & -7.569202 & 109.02680 & Akurat \\
\hline Ruangan & 2021 08:36 & & & & & \\
\hline $\begin{array}{l}\text { Di Luar } \\
\text { Ruangan }\end{array}$ & $\begin{array}{c}29-06- \\
202113: 50\end{array}$ & -7.4139 & 109.27179 & -7.4140 & 109.27180 & Akurat \\
\hline
\end{tabular}

Pada percobaan pertama pengujian GPS di desa Jambusari, kecamatan Jeruklegi, kabupaten Cilacap pada hari Senin tanggal 28 Juni 2021 pukul 08:36, dari hasil pengujian lokasi oleh modul GPS dari luar ruangan didapat hasil perbedaan latitude dan longitude dari modul GPS dan google maps yang tidak beda jauh dari jarak sebenarnya $\pm 10 \mathrm{~m}$. Pengujian GPS pada percobaan pertama dapat dilihat pada Gambar 5 berikut.
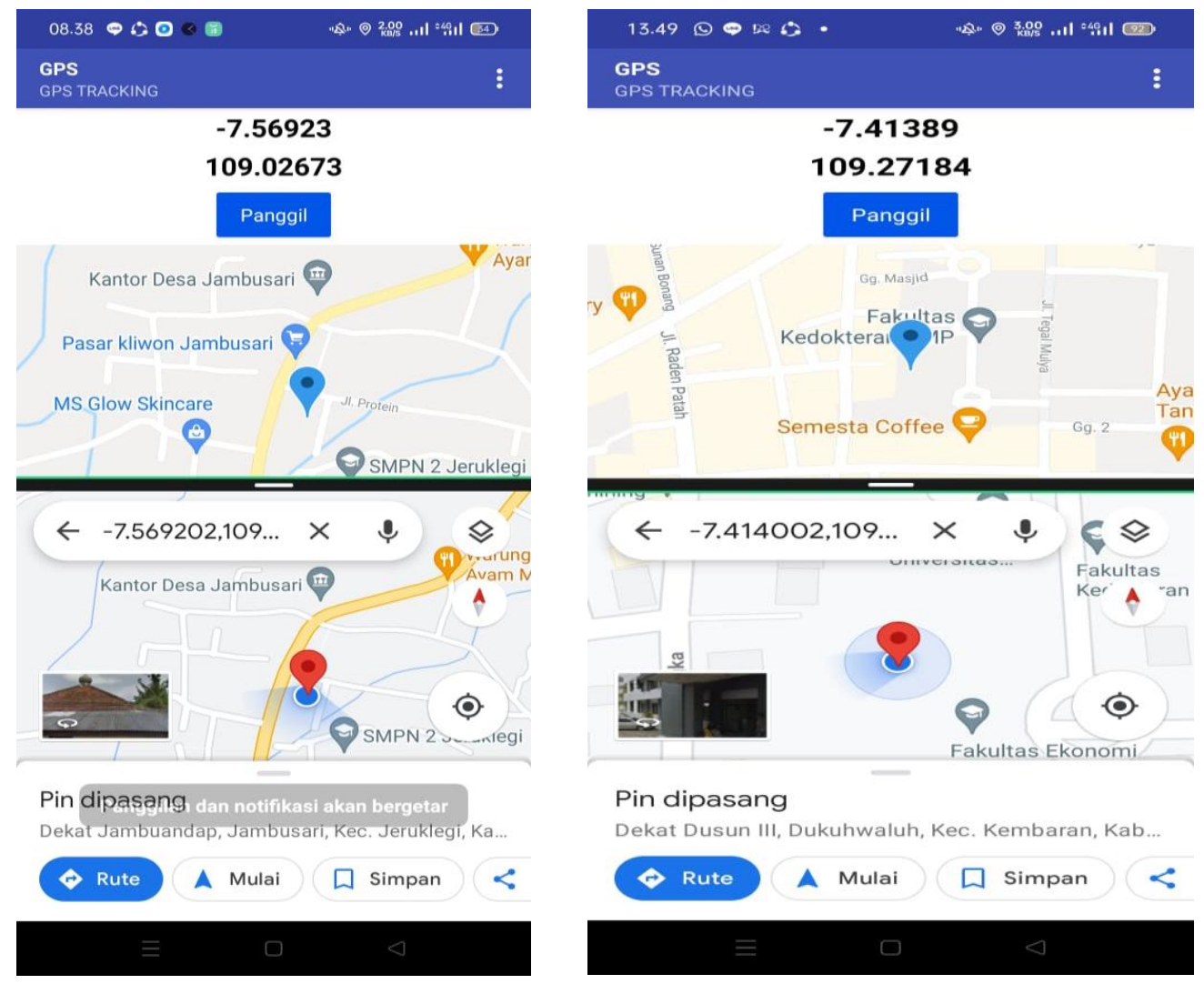

Gambar 5. Pengujian GPS Percobaan Pertama dan Pengujian GPS Percobaan Kedua 
Pada percobaan kedua dilakukan pengujian GPS di depan Fakultas Teknik dan Sains Universitas Muhammadiyah Purwokerto pada hari Selasa tanggal 29 Juni 2021 pukul 13:50, dari hasil pengujian lokasi oleh modul GPS dari luar ruangan didapat hasil perbedaan latitude dan longitude dari modul GPS dan Google Maps yang tidak beda jauh dari jarak sebenarnya $\pm 10 \mathrm{~m}$. Pengujian GPS pada percobaan pertama dapat dilihat pada Gambar 6.

\section{KESIMPULAN}

Alat bantu tunanetra berupa tongkat yang dibuat telah bekerja dengan baik dan dapat mendeteksi halangan dengan sesuai rancangan yaitu jarak $<70 \mathrm{~cm}$ dengan informasi berupa suara untuk berbelok ke kanan atau kiri sesuai keadaan medan. Alat juga dapat mendeteksi genangan air dan tombol emergency dapat berfungsi dengan baik dapat memberitahukan keberadaan koordinat lokasi si pemakai alat bantu ini melalui aplikasi yang telah dibuat yang dapat dipantau melalui smartphone keluarga si pemakai alat ini melalui jaringan internet.

\section{DAFTAR PUSTAKA}

[1] http://www.harianjogja.com/baca/2016/01/26/penyandang-disabilitas-375-juta-tunanetra-tuntut-hak-bersekolah684663 (diakses pada tanggal 3 Juli 2021)

[2] Andreas, W. W. (2016). Tongkat Bantu Tunanetra Pendeteksi Halangan Menggunakan Sensor Ultrasonik Berbasis Mikrokontroler Arduino. Jurnal Ilmiah Go Infotech, 22(1), 24-30.

[3] Kamila, A. R. (2019). Rancang Bangun Tongkat Bantu Tunanetra Pendeteksi Penghalang Dan Air. Seminar Nasional Teknik Elektro, 4(2), 252-256.

[4] Supriyadi, T. (2019). Tongkat Pintar Sebagai Alat Bantu Pemantau Keberadaan Penyandang Tunanetra Melalui Smartphone. Prosiding-Seminar Nasional Teknik Elektro UIN Sunan Gunung Djati Bandung, 181-191.

[5] Nasution, Syahrul Ardiansyah (2020). Rancang Bangun Sistem Pemandu Ruang Bagi Tunanetra Menggunakan Sensor Ultrasonik Dan Penentu Lokasi Berbasis Atmega2560, Skripsi. Universitas Islam Negeri Sumatera Utara. Medan

[6] Faruk, Z. (2017). Rancang Bangun Alat Bantu Jalan Tunanetra Dengan Tongkat Cerdas Berbasis Arduino. Institut Teknologi Nasional Malang

[7] Agusta, A. R., Andjarwirawan, J., \& Lim, R. (2019). Implementasi Internet of Things Untuk Menjaga Kelembaban Udara

[8] Bachtiar, L. (2020). Pengembangan Teknologi Mobile Untuk Sistem Kasir Rumah Makan Di Kota Sampit Menggunakan Firebase Realtime Database. Jurnal Teknologi Informasi Universitas Lambung Mangkurat (JTIULM), $5(2), 57-66$.

[9] Firza, M. N. (2019). Rancang Bangun Sistem Kendali Kendaraan Darat Tanpa Awak Pendeteksi Ranjau Berbasis IoT (Internet Of Thing). Politeknik Negeri Sriwijaya

[10] Friendy, F. (2019). Rancang Bangun Tongkat Tunanetra Menggunakan Sensor Ultrasonik Dengan Gps Tracking Berbasis Mikrokontroler. Universitas Komputer Indonesia. 
